\title{
Measuring Surgery Outcomes of Lung Cancer Patients with Concomitant Pulmonary Fibrosis: A Review of the Literature
}

\author{
Taichiro Goto \\ Lung Cancer and Respiratory Disease Center, Yamanashi Central Hospital, Kofu 400-8506, Japan; \\ taichiro@1997.jukuin.keio.ac.jp; Tel.: +81-55-253-7111
}

Received: 22 May 2018; Accepted: 30 June 2018; Published: 4 July 2018

\begin{abstract}
Idiopathic pulmonary fibrosis (IPF), the most common form of idiopathic interstitial pneumonias, often progresses to restrictive respiratory disturbance and mortality, typically within 10 years. IPF frequently coexists with lung cancer, and the combination of these two disease entities is far more difficult to treat than either lung cancer or IPF alone. In particular, surgery for lung cancer with IPF in the background increases postoperative morbidity and mortality by exacerbating pre-existing IPF, i.e., acute exacerbation of IPF (AEIPF). Furthermore, the long-term outcome after lung cancer surgery is considerably worsened by the presence of IPF. We present here a comprehensive review of AEIPF and the long-term outcomes after surgery.
\end{abstract}

Keywords: lung cancer; idiopathic pulmonary fibrosis; surgery; acute exacerbation; interstitial lung diseases

\section{Introduction}

Interstitial pneumonia (IP) is a known risk factor for lung cancer. The prevalence of IP in patients with lung cancer is approximately 4-8\% [1-3]. Idiopathic pulmonary fibrosis (IPF) is considered an independent risk factor for lung cancer [4-7], such that patients with IPF experience a 7- to 14-fold greater risk of lung cancer than the general population [8]. Some reports have shown that approximately $10 \%$ of the deaths among IPF patients are due to lung cancer [4]. Idiopathic interstitial pneumonia (IIP) constitutes the most common form of interstitial lung disease associated with lung cancer, but this can be a challenging differential diagnosis, as IIP is often overlooked in the diagnosis and treatment of lung cancer. Thus, IP evaluation in clinical cases of IIP-associated lung cancer comprises a heterogenous disease group consisting of various pathological conditions with different risks for acute exacerbation (AE) spread over multiple disease stages; thus, the interpretation of study results is extremely complicated. Anti-cancer therapies for patients with IP-associated lung cancer include radiotherapy, chemotherapy and surgical therapy, any of which can cause AE and/or fatal complications. Thus, careful selection of a suitable treatment strategy is required. The aims of this article are to review the current status regarding the outcomes of lung resection for lung cancer patients with concomitant IPF and to address the prediction and prevention of AE, focusing on the outlook for the future. The available literature was examined using references from MEDLINE. The search strategy included the following keywords: 'lung cancer', 'idiopathic pulmonary fibrosis', 'interstitial lung diseases', 'surgery', 'acute exerbation', 'complication', 'morbidity', 'mortality', 'recurrence', 'prognosis' and 'outcome', and included articles published from August 1996 to May 2018. A total of 63 papers were ultimately accepted for this review. 


\section{Interstitial Pneumonia-Associated Lung Cancer and Surgery}

IPF is the most common form of IIP and is associated with poor prognosis, with a mean post-diagnosis survival of 3-5 years [9-11]. IPF frequently coexists with lung cancer [4-6]. In IPF patients and IIP patients with lung cancer, p53 overexpression/mutation is frequently detected in fibrotic foci and the surrounding alveolar and bronchiolar epithelia, along with mutations of $K$-ras and the tumor suppressor gene FHIT [12-16]. These data suggest that IPF itself is a precancerous lesion. IPF-associated lung cancer is often encountered in daily clinical practice and is associated with difficulty in treatment selection due to poor prognosis of IIP, particularly IPF [7]. Furthermore, chemotherapy, radiotherapy and surgical therapy can all trigger AE [7]. Compared with lung cancer patients without IP, patients with IP-associated lung cancer are more likely to be older male and heavy smokers, with a histological diagnosis of squamous cell carcinoma $[17,18]$. This carcinoma commonly occurs in the distal dorsal side of the lower lobe, which tends to be severely affected by IPF, suggesting that IPF-associated persistent chronic inflammation plays a role in cancer development. Acute exacerbation of idiopathic pulmonary fibrosis (AEIPF) is characterized by diffuse and rapid alveolar damage on a background of IPF, which most likely occurs as a result of a massive lung injury from an unknown etiologic agent. Acute respiratory distress syndrome (ARDS) can also occur after surgery for lung cancer, with especially high incidence and mortality rates after pneumonectomy [19-21]. Thus, postoperative AE of IP can be a condition in which ARDS has occurred in a patient with IP-associated lung cancer who has undergone surgery. A Japanese nationwide survey for respiratory surgeries conducted in 2009 showed that 268 surgery-related deaths occurred after surgery in 231,301 cases of lung cancer $(0.86 \%)$ [22]. The most common cause of death was AE of IP in 68 cases, constituting $25 \%$ of all surgery-related deaths. Thus, postoperative AE of IP remains an important problem that needs to be addressed.

\section{Pathology of the Microscopic Usual Interstitial Pneumonia Pattern}

AEIPF of the usual interstitial pneumonia (UIP) pattern is pathologically recognized as a diffuse alveolar damage in UIP [23]. In spite of the absence of any radiological findings of IPF, it does rarely happen that postoperative histology of the background lung reveals a UIP pattern in some patients, and this pattern suggests early-stage IPF and can be defined as microscopic UIP $[24,25]$. We previously reported a patient who showed AE of microscopic UIP after lung cancer surgery (Figure 1). Even such a microscopic UIP pattern may become exacerbated after chest surgery [26].

The diagnostic criteria for IPF comprise a spatially and temporally heterogeneous appearance of the tissue; alternating zones of normal lung with patchy interstitial widening from a combination of inflammation and fibrosis, active fibroblastic foci, peripheral distribution of fibrotic changes in the lobule, and honeycomb changes (Figure 1) [27]. The diagnosis of IPF necessitates the exclusion of other types of IP, such as interstitial lung diseases associated with a systemic condition, medications, or environmental pathogen exposure [11].

We also reported the presence of IPF to be a risk factor for postoperative mortality, mainly due to the occurrence of $\mathrm{AE}$ [18]. In addition, long-term survival turned out to be poor, especially in patients with stage I/II non-small cell lung cancer, with respiratory failure being mainly responsible for death in the late phase [18]. Thus, this microscopic UIP pattern, which cannot be detected by radiological examination, complicates the selection of treatment for lung cancer. 


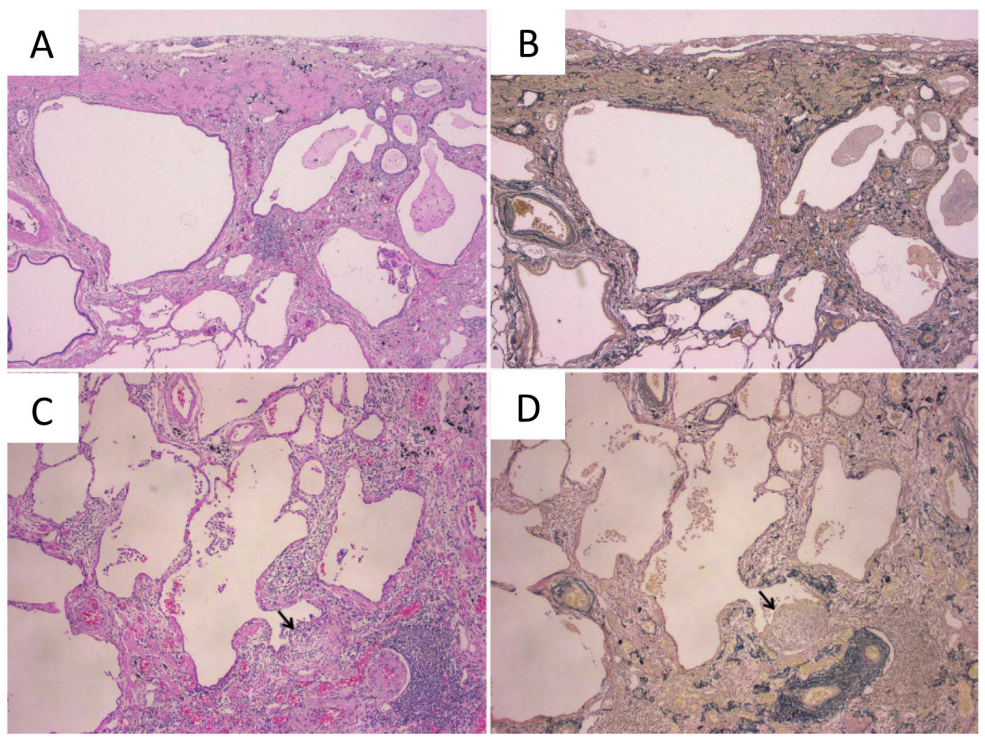

Figure 1. Histopathology of the microscopic usual interstitial pneumonia (UIP) pattern. (A,B) Microscopic UIP pattern in the background lung. (C,D) The arrow indicates active fibroblastic foci (A,C, Hematoxylin and eosin staining; B,D, Elastica-van Gieson staining). This figure is adapted from Goto T. Ann Thorac Cardiovasc Surg (2011) 17, 573-576 [26].

\section{Risk Factors for Postoperative Acute Exacerbation}

A major challenge in the treatment of IP-associated lung cancer is the extremely fatal nature of AE of IP, which is often induced by the cancer treatment itself. For IP-associated lung cancer, radiotherapy is generally contraindicated and the applicability of chemotherapy regimens is also limited. In particular, irinotecan, gemcitabine and amrubicin are, respectively, contraindicated in these patients. Surgery is often selected for resectable tumors in the treatment of such cancer, even though surgery is also a known risk factor for AE. The incidence of postoperative AE of IP varies among patients by their demographics and IP subtypes. Sugiura et al. reported the finding of honeycombing on $\mathrm{CT}$ imaging to be a potential risk factor for $\mathrm{AE}$ after lung cancer surgery [28]. As earlier reports were generally of a small scale and did not provide a clear definition of postoperative $\mathrm{AE}$, a varying incidence of $0-44.4 \%$ and even more widely varying mortality rates of $0-100 \%$ are reported. The incidence and mortality of postoperative AEIPF are reviewed in Table 1 [1-3,18,29-46].

A recent multicenter retrospective cohort study conducted by the Japanese Association for Chest Surgery included 1763 cases, which was much larger and thus expected to provide more reliable findings than previous surveys, reported an incidence of $\mathrm{AE}$ in the first 30 postoperative days of $9.3 \%$ and mortality rate of $43.9 \%$ [43]. This study was intended to clarify the predictive risk factors of AEIPF after lung resection. The study included patients with IP-associated lung cancer diagnosed during a 10-year period from 2000 to 2009 and evaluated the incidence of $\mathrm{AE}$ as the primary endpoint and overall survival as the secondary endpoint. The survey consisted of 82 questions regarding patient demographics, as well as factors related to lung cancer, IP and surgery, with information obtained within 1 month of the surgery, including postoperative complications, AE and outcome. The efficacy of AE prophylaxis was unclear. Univariate analysis revealed significant correlations with AE for the following factors: gender, preoperative $\mathrm{AE}$ of IP, preoperative history of steroid use, preoperative CRP (C-reactive protein), LDH (lactate dehydrogenase), KL-6 (Krebs von den Lungen-6), \%VC (vital capacity), FEV1.0 (forced expiratory volume in $1 \mathrm{~s}$ ), FEV1.0\%, DLCO (carbon monoxide diffusing capacity of the lung), operative time, blood loss, imaging findings of IP, and the surgical procedure used. A subsequent multivariate analysis of these factors identified the following as significant respective risk factors for AE: male gender, preoperative steroid use, KL-6 $>1000 \mathrm{U} / \mathrm{mL}, \% \mathrm{VC}<80 \%$, UIP pattern, history of $\mathrm{AE}$, segmentectomy or a more extensive surgical procedure (reference, wedge resection). 
Table 1. Reports on postoperative acute exacerbation of idiopathic pulmonary fibrosis in non-small cell lung cancer patients with idiopathic pulmonary fibrosis.

\begin{tabular}{|c|c|c|c|c|c|c|c|}
\hline Author & Ref. & $\begin{array}{l}\text { Published } \\
\text { Year }\end{array}$ & $\begin{array}{l}\text { No of Pts } \\
\text { with IPF }\end{array}$ & $\begin{array}{c}\text { No of Pts } \\
\text { with AEIPF }\end{array}$ & $\begin{array}{l}\text { Incidence of } \\
\text { AEIPF (\%) }\end{array}$ & $\begin{array}{l}\text { Death of } \\
\text { AEIPF }\end{array}$ & $\begin{array}{l}\text { Mortality of Pts } \\
\text { with AEIPF (\%) }\end{array}$ \\
\hline Fujimoto & [32] & 2003 & 21 & 0 & 0.0 & 0 & 0.0 \\
\hline Kumar & [35] & 2003 & 24 & 5 & 20.8 & 4 & 80.0 \\
\hline Chiyo & [31] & 2003 & 36 & 9 & 25.0 & 3 & 33.3 \\
\hline Koizumi & [34] & 2004 & 47 & 7 & 14.9 & 6 & 85.7 \\
\hline Okamoto & [39] & 2004 & 20 & 4 & 20.0 & 3 & 75.0 \\
\hline Kushibe & [36] & 2007 & 33 & 4 & 12.1 & 4 & 100.0 \\
\hline Watanabe & {$[3]$} & 2008 & 54 & 4 & 7.4 & 4 & 100.0 \\
\hline Chida & [30] & 2008 & 91 & 11 & 12.1 & 7 & 63.6 \\
\hline Minegishi & [37] & 2009 & 35 & 8 & 8.6 & 3 & 37.5 \\
\hline Shintani & [44] & 2010 & 40 & 6 & 15.0 & 5 & 83.3 \\
\hline Yano & [46] & 2011 & 7 & 1 & 14.3 & 0 & 0.0 \\
\hline Suzuki & [45] & 2011 & 28 & 9 & 32.0 & 0 & 0.0 \\
\hline Saito & {$[1]$} & 2011 & 28 & 3 & 11.7 & 0 & 0.0 \\
\hline Park & [42] & 2011 & 100 & 28 & 28.0 & 13 & 46.4 \\
\hline Chida & [29] & 2012 & 52 & 6 & 11.5 & 3 & 50.0 \\
\hline Mizuno & [38] & 2012 & 52 & 7 & 13.5 & 6 & 85.7 \\
\hline Voltolini & [2] & 2013 & 37 & 5 & 13.5 & 3 & 60.0 \\
\hline Sato & [43] & 2014 & 1763 & 164 & 9.3 & 72 & 43.9 \\
\hline Goto & [18] & 2014 & 65 & 4 & 6.2 & 4 & 100.0 \\
\hline Omori & [40] & 2015 & 103 & 5 & 4.9 & 3 & 60.0 \\
\hline Joo & [33] & 2016 & 80 & 6 & 7.5 & - & - \\
\hline Otsuka & [41] & 2016 & 9 & 4 & 44.4 & 3 & 75.0 \\
\hline
\end{tabular}

Ref: reference, Pts: patients, IPF: idiopathic pulmonary fibrosis, AEIPF: acute exacerbation of IPF.

In this study, most of the patients (64.6\%) had an onset of AE within 10 days after operation, and postoperative day 4 showed the highest frequency of onset [43]. Compared with the $0.34 \%$ postoperative mortality rate for lung cancer reported by the Japanese Association for Thoracic Surgery [47], the mortality rate after surgery for IP-associated lung cancer suggests an extremely high risk in surgery. Moreover, patients with a prior history of $\mathrm{AE}$ tend to experience recurrence of $\mathrm{AE}$ or continue to suffer from the respiratory dysfunction caused by $\mathrm{AE}$, leading to a poor long-term outcome.

Previously reported risk factors for AE include low vital capacity, low diffusing capacity, high serum CRP, high serum IP markers (e.g., LDH, SP-D, KL-6), longer operative time, thoracotomy rather than thoracoscopy, lobectomy rather than limited surgery, imaging findings of fibrosis, UIP pattern as a subtype of IP, intraoperative fluid balance, and intraoperative inhalation of high-concentration oxygen. However, the definitive risk factors have remained unclear due to the small sample size of previous studies, as mentioned above, and also the variability of the study settings. In the aforementioned large-scale survey conducted by the Japanese Association for Chest Surgery, seven of the aforementioned conventional risk factors were identified as significant independent risk factors for AE [48]: prior history of AE (assigned score 5), UIP pattern (4), anatomical segmentectomy or more extensive surgical procedure (4), male gender (3), preoperative steroid use (3), preoperative serum KL-6 > $1000 \mathrm{U} / \mathrm{mL}$ (2) and preoperative \%VC < 80 (1). Each of the seven factors was assigned a score (as indicated in parentheses) and the additive scores for each factor were the risk score (RS) for predicting exacerbation. The patients were classified into three groups based on the RS: low risk (RS: 0-10), intermediate risk (RS: 11-14), and high risk (RS: 15-22) groups [48]. This RS has yet to be validated, but is expected to enable a comparison of postoperative AE in patients, matched by background risk factors, and will facilitate evaluation of new preventative and therapeutic approaches as well as identification of appropriate treatment strategies based on risk comparison with other therapies, such as anticancer agents and radiotherapy. 


\section{Strategies for Preventing Acute Exacerbation}

\subsection{Surgery and Selection of the Surgical Procedures}

In the aforementioned RS-based exacerbation risk prediction system [48], there is a four-point difference in score between anatomical segmentectomy or more extensive surgical procedure and partial resection. Thus, the selection of partial resection reduces the risk of exacerbation. However, the same survey data also indicate that limited surgery, which increases the risk for cancer recurrence as mentioned earlier, does not provide survival benefit in patients with IP-associated lung cancer [49]. The study also showed that patients with a preoperative $\% \mathrm{VC}$ of $\leq 80 \%$, including those in stage IA, had poor prognosis, with a 5-year postoperative survival of 20\% [49], suggesting the importance of the preoperative evaluation of the exacerbation risk and selection of an appropriate surgical procedure, as well as careful determination of surgical indication.

Stereotactic radiotherapy (SRT) is increasingly used to treat lung cancer as a substitute for surgery. SRT involves multidirectional irradiation of a small region to enable dose convergence and has demonstrated a treatment outcome comparable to that achieved by surgery in early-stage lung cancer [50]. The impact of interstitial changes on radiation pneumonitis after SRT remains controversial. Some reports show that the presence of asymptomatic IP that is detectable by chest CT is not a significant risk factor for the grade $2-5$ radiation pneumonitis caused by SRT [51], whereas other studies suggest the presence of interstitial changes to be an indicator of radiation pneumonitis after SRT [52,53]. Further studies are, therefore, needed to evaluate the efficacy of SRT in treating IP-associated lung cancer.

\subsection{Intraoperative Management}

Hyperextension of the lung caused by positive pressure ventilation with a ventilator and administration of high-concentration oxygen is a known cause of lung injury. Such injury aggravates severely fibrotic lungs with reduced compliance, indicating that hyperoxia, barotrauma, and volutrauma may induce diffuse alveolar damage [54]. During surgery for IP-associated lung cancer, intraoperative management to minimize the intraoperative fraction of inspired oxygen and airway pressure is implemented in many institutions. Nevertheless, the efficacy and safety of these intraoperative management practices remain yet to be evaluated.

\subsection{Prophylactic Agents}

Previous large-scale retrospective studies have included patients treated with steroids, macrolides, ulinastatin, sivelestat sodium, or other agents for the prevention of postoperative AE, although none of these agents has proven to be effective.

As mentioned in the previous section, preoperative steroid use has been identified as a risk factor for exacerbation. Although this may be due to selection bias in favor of severe cases, such as those requiring steroids, multiple previous studies have shown steroid use to be a risk factor for exacerbation [55]. For the treatment of IPF, the most common subtype of IP, the oral anti-fibrotic agent pirfenidone was demonstrated to improve progression-free survival by suppressing progression of IPF in a recent phase III trial [56]. However, the efficacy of pirfenidone in high exacerbation risk settings, such as during the perioperative period, remains to be established. Iwata et al. treated patients with lung cancer associated with IPF with perioperative pirfenidone and noted no serious adverse reactions or occurrence of exacerbation within 30 days of surgery $[57,58]$. Given that patients treated perioperatively with pirfenidone displayed reduced serum KL-6 levels and reduced intensity of lung injury in resected specimens, it may be possible that the agent exerts its effect by suppressing the perioperative activity of IPF $[57,58]$. Iwata et al. also conducted a multicenter prospective phase II trial (WJOG6711L: PEOPLE study) and reported favorable results, where only two of 39 eligible patients (5.1\%) and one of 36 patients who completed the protocol (2.8\%) experienced exacerbation [59]. However, this study was conducted using a single-arm design with a small sample size [59] and 
the results need to be verified in a larger-scale phase III trial. Nintedanib is another agent with IPF treatment efficacy reported in a phase III trial, but its label recommends discontinuation of its use in the perioperative period due to its potential to delay wound healing. Therefore, when using nintedanib for the prevention of postoperative $\mathrm{AE}$, careful review of the information on adverse reactions must be performed to confirm the safety of the perioperative use of the agent.

\section{Postoperative Outcome and Prognostic Factors in Interstitial Pneumonia-Associated Lung Cancer}

Few investigators have reported on the long-term outcome after lung resection for non-small cell lung cancer patients with IPF. A large-scale survey conducted by the Japanese Association for Chest Surgery showed that the 5-year postoperative survival of IP-associated lung cancer was as low as $40 \%$ in the entire population and 59\% in those with stage-IA disease [49], which are much worse survival rates than those reported in a survey conducted by the Japanese Joint Committee for Lung Cancer Registration (86.8\% for stage IA). Multivariate analysis identified wedge resection, $\% \mathrm{VC}<80 \%$ and tumors located in the inferior lobe as poor prognostic factors. When analysis was limited to stage-IA patients, the survival curves for those treated with wedge resection and those treated with lung lobectomy crossed at approximately 1 year after surgery, with a 5-year survival of $29.2 \%$ with wedge resection and $68.6 \%$ with lobectomy ( $P=0.0008$, Figure 2$)$. These results demonstrate that wedge resection is associated with a lower incidence of AE and better short-term outcome, but with a higher rate of cancer recurrence and worse long-term outcome compared to lobectomy. An appropriate strategy must be adopted, such as selecting wedge resection for patients at high risk of postoperative AE and anatomical curative resection for lower-risk patients. It should be noted that adjuvant chemotherapy is not recommended, due to its limited efficacy and the potential risk for inducing AEIPF. Thus, these patients are generally treated with surgery alone.

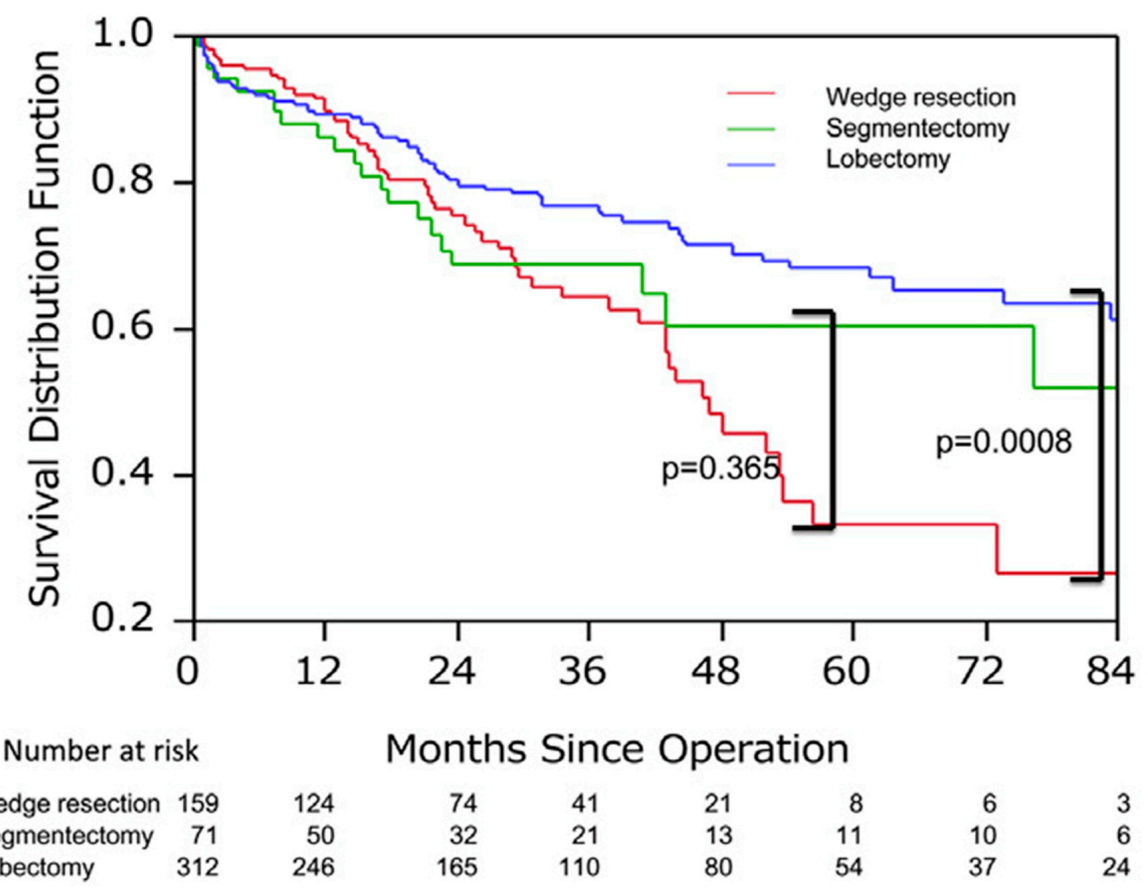

Figure 2. The survival associated with the surgical procedure in patients with stage IA interstitial pneumonia (IP)-associated lung cancer. 5-year survival of the wedge resection group (29.2\%) was significantly worse than that of segmentectomy $(60.0 \%)$ or lobectomy group $(68.6 \%)$. This figure is adapted from Sato T. J Thorac Cardiovasc Surg (2015) 149, 64-70 [49]. 
Watanabe et al. reported that the 5-year survival rates were $61.6 \%$ in pathological stage IA lung cancer patients with IPF and $83.0 \%$ in those without IPF. In addition, 5-year recurrence-free survival was $56.0 \%$ and $83.1 \%$, respectively [3]. Likewise, Saito et al. reported that 5-year survival rates for pathologic stage I lung cancer were significantly different between patients with IPF (54.2\%) and those without IPF (88.3\%). [1]. These results and other reported data pertaining to the long-term outcome are reviewed in Table $2[1-3,17,31,60,61]$. Lung cancer in the presence of IP may be associated with smoking as a background factor and be of high biological malignancy. The lungs of patients with IP are at high risk for cancer development and also appear to be at increased risk for recurrent multiple cancers after the initial resection $[4,62,63]$. IP itself is generally associated with progression of IP and poor prognosis; it is noteworthy that death from $\mathrm{AE}$ and subsequent respiratory failure also affect the prognosis of patients with IP-associated lung cancer [31,49]. IP may also limit treatment options for recurrent lung cancer, precluding the use of aggressive anticancer treatment and/or radiotherapy [18]. These complex factors are likely to contribute to the poorer prognosis of lung cancer patients with IP than those without IP.

Table 2. Reports on the long-term outcome of non-small cell lung cancer patients with idiopathic pulmonary fibrosis after lung resection.

\begin{tabular}{ccccccc}
\hline \multirow{2}{*}{ Author } & Ref. & Year & Pts with IPF & Pts without IPF & 5-Year Survival \\
\hline Kawasaki & {$[60]$} & 2002 & 53 & 658 & 53.0 & IPF (-) \\
Chiyo & {$[31]$} & 2003 & 36 & 895 & 35.6 & 71.0 \\
Watanabe & {$[3]$} & 2008 & 56 & 802 & 61.6 & 83.0 \\
Saito & {$[1]$} & 2011 & 28 & 322 & 54.2 & 88.3 \\
Voltolini & {$[2]$} & 2013 & 37 & 738 & 52.0 & 65.0 \\
Sekine & {$[61]$} & 2014 & 41 & 339 & 36.9 & 66.1 \\
Lee & {$[17]$} & 2014 & 33 & 66 & 73.0 & 38.0 \\
\hline
\end{tabular}

\section{Conclusions}

For the surgical treatment of IP-associated lung cancer, surgical indication and surgical procedures should be carefully determined based on the available evidence. Recent studies have offered additional data regarding the outcome, incidence of postoperative AE and risk factors associated with surgery for IP-associated lung cancer. Promising drugs are available for the prevention of postoperative AE, but require further validation. Developing a safe and effective treatment for IP-associated lung cancer is an urgent task. A new treatment strategy based on the biological or genomic characteristics of IP should be established through novel translational research and large-scale clinical trials.

Funding: This research received no external funding.

Acknowledgments: The author greatly appreciate the help of Yoshihiro Miyashita, Yumiko Kakizaki, and Toshiharu Tsutsui for their scientific discussion.

Conflicts of Interest: The author declare no conflict of interest.

\section{References}

1. Saito, Y.; Kawai, Y.; Takahashi, N.; Ikeya, T.; Murai, K.; Kawabata, Y.; Hoshi, E. Survival after surgery for pathologic stage IA non-small cell lung cancer associated with idiopathic pulmonary fibrosis. Ann. Thorac. Surg. 2011, 92, 1812-1817. [CrossRef] [PubMed]

2. Voltolini, L.; Bongiolatti, S.; Luzzi, L.; Bargagli, E.; Fossi, A.; Ghiribelli, C.; Rottoli, P.; Gotti, G. Impact of interstitial lung disease on short-term and long-term survival of patients undergoing surgery for non-small-cell lung cancer: Analysis of risk factors. Eur. J. Cardiothorac. Surg. 2013, 43, e17-e23. [CrossRef] [PubMed] 
3. Watanabe, A.; Higami, T.; Ohori, S.; Koyanagi, T.; Nakashima, S.; Mawatari, T. Is lung cancer resection indicated in patients with idiopathic pulmonary fibrosis? J. Thorac. Cardiovasc. Surg. 2008, 136, 1357-1363. [CrossRef] [PubMed]

4. Hubbard, R.; Venn, A.; Lewis, S.; Britton, J. Lung cancer and cryptogenic fibrosing alveolitis. A population-based cohort study. Am. J. Respir. Crit. Care Med. 2000, 161, 5-8. [CrossRef] [PubMed]

5. American Thoracic Society; European Respiratory Society. American Thoracic Society/European Respiratory Society International Multidisciplinary Consensus Classification of the Idiopathic Interstitial Pneumonias. This joint statement of the American Thoracic Society (ATS), and the European Respiratory Society (ERS) was adopted by the ATS board of directors, June 2001 and by the ERS Executive Committee, June 2001. Am. J. Respir. Crit. Care Med. 2002, 165, 277-304. [CrossRef]

6. Ozawa, Y.; Suda, T.; Naito, T.; Enomoto, N.; Hashimoto, D.; Fujisawa, T.; Nakamura, Y.; Inui, N.; Nakamura, H.; Chida, K. Cumulative incidence of and predictive factors for lung cancer in IPF. Respirology 2009, 14, 723-728. [CrossRef] [PubMed]

7. Kreuter, M.; Ehlers-Tenenbaum, S.; Schaaf, M.; Oltmanns, U.; Palmowski, K.; Hoffmann, H.; Schnabel, P.A.; Heussel, C.P.; Puderbach, M.; Herth, F.J.; et al. Treatment and outcome of lung cancer in idiopathic interstitial pneumonias. Sarcoidosis Vasc. Diffus. Lung. Dis. 2015, 31, 266-274.

8. Raghu, G.; Nyberg, F.; Morgan, G. The epidemiology of interstitial lung disease and its association with lung cancer. Br. J. Cancer 2004, 91 (Suppl. 2), S3-S10. [CrossRef] [PubMed]

9. Flaherty, K.R.; Toews, G.B.; Travis, W.D.; Colby, T.V.; Kazerooni, E.A.; Gross, B.H.; Jain, A.; Strawderman, R.L., 3rd; Paine, R.; Flint, A.; et al. Clinical significance of histological classification of idiopathic interstitial pneumonia. Eur. Respir. J. 2002, 19, 275-283. [CrossRef] [PubMed]

10. Rudd, R.M.; Prescott, R.J.; Chalmers, J.C.; Johnston, I.D.; Fibrosing Alveolitis Subcommittee of the Research Committee of the British Thoracic Society. British Thoracic Society Study on cryptogenic fibrosing alveolitis: Response to treatment and survival. Thorax 2007, 62, 62-66. [CrossRef] [PubMed]

11. Raghu, G.; Collard, H.R.; Egan, J.J.; Martinez, F.J.; Behr, J.; Brown, K.K.; Colby, T.V.; Cordier, J.F.; Flaherty, K.R.; Lasky, J.A.; et al. An official ATS/ERS/JRS/ALAT statement: Idiopathic pulmonary fibrosis: Evidence-based guidelines for diagnosis and management. Am. J. Respir. Crit. Care Med. 2011, 183, 788-824. [CrossRef] [PubMed]

12. Kuwano, K.; Kunitake, R.; Kawasaki, M.; Nomoto, Y.; Hagimoto, N.; Nakanishi, Y.; Hara, N. P21Waf1/Cip1/Sdi1 and p53 expression in association with DNA strand breaks in idiopathic pulmonary fibrosis. Am. J. Respir. Crit. Care Med. 1996, 154, 477-483. [CrossRef] [PubMed]

13. Hojo, S.; Fujita, J.; Yamadori, I.; Kamei, T.; Yoshinouchi, T.; Ohtsuki, Y.; Okada, H.; Bandoh, S.; Yamaji, Y.; Takahara, J.; et al. Heterogeneous point mutations of the p53 gene in pulmonary fibrosis. Eur. Respir. J. 1998, 12, 1404-1408. [CrossRef] [PubMed]

14. Vassilakis, D.A.; Sourvinos, G.; Spandidos, D.A.; Siafakas, N.M.; Bouros, D. Frequent genetic alterations at the microsatellite level in cytologic sputum samples of patients with idiopathic pulmonary fibrosis. Am. J. Respir. Crit. Care Med. 2000, 162, 1115-1119. [CrossRef] [PubMed]

15. Uematsu, K.; Yoshimura, A.; Gemma, A.; Mochimaru, H.; Hosoya, Y.; Kunugi, S.; Matsuda, K.; Seike, M.; Kurimoto, F.; Takenaka, K.; et al. Aberrations in the fragile histidine triad (FHIT) gene in idiopathic pulmonary fibrosis. Cancer Res. 2001, 61, 8527-8533. [PubMed]

16. Takahashi, T.; Munakata, M.; Ohtsuka, Y.; Nisihara, H.; Nasuhara, Y.; Kamachi-Satoh, A.; Dosaka-Akita, H.; Homma, Y.; Kawakami, Y. Expression and alteration of ras and p53 proteins in patients with lung carcinoma accompanied by idiopathic pulmonary fibrosis. Cancer 2002, 95, 624-633. [CrossRef] [PubMed]

17. Lee, T.; Park, J.Y.; Lee, H.Y.; Cho, Y.J.; Yoon, H.I.; Lee, J.H.; Jheon, S.; Lee, C.T.; Park, J.S. Lung cancer in patients with idiopathic pulmonary fibrosis: Clinical characteristics and impact on survival. Respir. Med. 2014, 108, 1549-1555. [CrossRef] [PubMed]

18. Goto, T.; Maeshima, A.; Oyamada, Y.; Kato, R. Idiopathic pulmonary fibrosis as a prognostic factor in non-small cell lung cancer. Int. J. Clin. Oncol. 2014, 19, 266-273. [CrossRef] [PubMed]

19. Evans, R.G.; Naidu, B. Does a conservative fluid management strategy in the perioperative management of lung resection patients reduce the risk of acute lung injury? Interact. Cardiovasc. Thorac. Surg. 2012, 15, 498-504. [CrossRef] [PubMed]

20. Kometani, T.; Okamoto, T.; Yoshida, S.; Yoshino, I. Acute respiratory distress syndrome after pulmonary resection. Gen. Thorac. Cardiovasc. Surg. 2013, 61, 504-512. [CrossRef] [PubMed] 
21. Peretti, M.; Hervochon, R.; Loi, M.; Blanc, K.; Roche, N.; Alifano, M. Predictors of post-pneumonectomy respiratory failure and ARDS: Usefulness of normalized pulmonary artery diameter. Intensive Care Med. 2018. [CrossRef] [PubMed]

22. Committee for Scientific, A.; Sakata, R.; Fujii, Y.; Kuwano, H. Thoracic and cardiovascular surgery in Japan during 2009: Annual report by the Japanese Association for Thoracic Surgery. Gen. Thorac. Cardiovasc. Surg. 2011, 59, 636-667. [CrossRef]

23. Kutlu, C.A.; Williams, E.A.; Evans, T.W.; Pastorino, U.; Goldstraw, P. Acute lung injury and acute respiratory distress syndrome after pulmonary resection. Ann. Thorac. Surg. 2000, 69, 376-380. [CrossRef]

24. Kawabata, Y.; Fukushima, K.; Uchiyama, T.; Sugita, H.; Kimura, B. [A focal usual interstitial pneumonia lesion: An important risk factor in diffuse alveolar damage-acute exacerbation of a focal usual interstitial pneumonia patient]. Nihon Kokyuki Gakkai Zasshi 2001, 39, 316-321. [PubMed]

25. Maniwa, T.; Kondo, H.; Mori, K.; Sato, T.; Teramukai, S.; Ebina, M.; Kishi, K.; Watanabe, A.; Sugiyama, Y.; Date, H. Outcomes in surgically managed non-small-cell lung cancer patients with evidence of interstitial pneumonia identified on preoperative radiology or incidentally on postoperative histology. Interact. Cardiovasc. Thorac. Surg. 2015, 20, 641-646. [CrossRef] [PubMed]

26. Goto, T.; Maeshima, A.; Akanabe, K.; Oyamada, Y.; Kato, R. Acute exacerbation of idiopathic pulmonary fibrosis of microscopic usual interstitial pneumonia pattern after lung cancer surgery. Ann. Thorac. Cardiovasc. Surg. 2011, 17, 573-576. [CrossRef] [PubMed]

27. Katzenstein, A.L.; Myers, J.L. Idiopathic pulmonary fibrosis: Clinical relevance of pathologic classification. Am. J. Respir. Crit. Care Med. 1998, 157, 1301-1315. [CrossRef] [PubMed]

28. Sugiura, H.; Takeda, A.; Hoshi, T.; Kawabata, Y.; Sayama, K.; Jinzaki, M.; Kuribayashi, S. Acute exacerbation of usual interstitial pneumonia after resection of lung cancer. Ann. Thorac. Surg. 2012, 93, 937-943. [CrossRef] [PubMed]

29. Chida, M.; Kobayashi, S.; Karube, Y.; Hayama, M.; Tamura, M.; Ishihama, H.; Oyaizu, T. Incidence of acute exacerbation of interstitial pneumonia in operated lung cancer: Institutional report and review. Ann. Thorac. Cardiovasc. Surg. 2012, 18, 314-317. [CrossRef] [PubMed]

30. Chida, M.; Ono, S.; Hoshikawa, Y.; Kondo, T. Subclinical idiopathic pulmonary fibrosis is also a risk factor of postoperative acute respiratory distress syndrome following thoracic surgery. Eur. J. Cardiothorac. Surg. 2008, 34, 878-881. [CrossRef] [PubMed]

31. Chiyo, M.; Sekine, Y.; Iwata, T.; Tatsumi, K.; Yasufuku, K.; Iyoda, A.; Otsuji, M.; Yoshida, S.; Shibuya, K.; Iizasa, T.; et al. Impact of interstitial lung disease on surgical morbidity and mortality for lung cancer: Analyses of short-term and long-term outcomes. J. Thorac. Cardiovasc. Surg. 2003, 126, 1141-1146. [CrossRef]

32. Fujimoto, T.; Okazaki, T.; Matsukura, T.; Hanawa, T.; Yamashita, N.; Nishimura, K.; Kuwabara, M.; Matsubara, Y. Operation for lung cancer in patients with idiopathic pulmonary fibrosis: Surgical contraindication? Ann. Thorac. Surg. 2003, 76, 1674-1678. [CrossRef]

33. Joo, S.; Kim, D.K.; Sim, H.J.; Lee, G.D.; Hwang, S.K.; Choi, S.; Kim, H.R.; Kim, Y.H.; Park, S.I. Clinical results of sublobar resection versus lobectomy or more extensive resection for lung cancer patients with idiopathic pulmonary fibrosis. J. Thorac. Dis. 2016, 8, 977-984. [CrossRef] [PubMed]

34. Koizumi, K.; Hirata, T.; Hirai, K.; Mikami, I.; Okada, D.; Yamagishi, S.; Kawashima, T.; Nakajima, Y.; Shimizu, K. Surgical treatment of lung cancer combined with interstitial pneumonia: The effect of surgical approach on postoperative acute exacerbation. Ann. Thorac. Cardiovasc. Surg. 2004, 10, 340-346. [PubMed]

35. Kumar, P.; Goldstraw, P.; Yamada, K.; Nicholson, A.G.; Wells, A.U.; Hansell, D.M.; Dubois, R.M.; Ladas, G. Pulmonary fibrosis and lung cancer: Risk and benefit analysis of pulmonary resection. J. Thorac. Cardiovasc. Surg. 2003, 125, 1321-1327. [CrossRef]

36. Kushibe, K.; Kawaguchi, T.; Takahama, M.; Kimura, M.; Tojo, T.; Taniguchi, S. Operative indications for lung cancer with idiopathic pulmonary fibrosis. Thorac. Cardiovasc. Surg. 2007, 55, 505-508. [CrossRef] [PubMed]

37. Minegishi, Y.; Takenaka, K.; Mizutani, H.; Sudoh, J.; Noro, R.; Okano, T.; Azuma, A.; Yoshimura, A.; Ando, M.; Tsuboi, E.; et al. Exacerbation of idiopathic interstitial pneumonias associated with lung cancer therapy. Intern. Med. 2009, 48, 665-672. [CrossRef] [PubMed]

38. Mizuno, Y.; Iwata, H.; Shirahashi, K.; Takamochi, K.; Oh, S.; Suzuki, K.; Takemura, H. The importance of intraoperative fluid balance for the prevention of postoperative acute exacerbation of idiopathic pulmonary fibrosis after pulmonary resection for primary lung cancer. Eur. J. Cardiothorac. Surg. 2012, 41, e161-e165. [CrossRef] [PubMed] 
39. Okamoto, T.; Gotoh, M.; Masuya, D.; Nakashima, T.; Liu, D.; Kameyama, K.; Ishikawa, S.; Yamamoto, Y.; Huang, C.L.; Yokomise, H. Clinical analysis of interstitial pneumonia after surgery for lung cancer. Jpn. J. Thorac. Cardiovasc. Surg. 2004, 52, 323-329. [CrossRef] [PubMed]

40. Omori, T.; Tajiri, M.; Baba, T.; Ogura, T.; Iwasawa, T.; Okudela, K.; Takemura, T.; Oba, M.S.; Maehara, T.; Nakayama, H.; et al. Pulmonary Resection for Lung Cancer in Patients With Idiopathic Interstitial Pneumonia. Ann. Thorac. Surg. 2015, 100, 954-960. [CrossRef] [PubMed]

41. Otsuka, H.; Sugino, K.; Hata, Y.; Makino, T.; Koezuka, S.; Isobe, K.; Tochigi, N.; Shibuya, K.; Homma, S.; Iyoda, A. Clinical features and outcomes of patients with lung cancer as well as combined pulmonary fibrosis and emphysema. Mol. Clin. Oncol. 2016, 5, 273-278. [CrossRef] [PubMed]

42. Park, J.S.; Kim, H.K.; Kim, K.; Kim, J.; Shim, Y.M.; Choi, Y.S. Prediction of acute pulmonary complications after resection of lung cancer in patients with preexisting interstitial lung disease. Thorac. Cardiovasc. Surg. 2011, 59, 148-152. [CrossRef] [PubMed]

43. Sato, T.; Teramukai, S.; Kondo, H.; Watanabe, A.; Ebina, M.; Kishi, K.; Fujii, Y.; Mitsudomi, T.; Yoshimura, M.; Maniwa, T.; et al. Impact and predictors of acute exacerbation of interstitial lung diseases after pulmonary resection for lung cancer. J. Thorac. Cardiovasc. Surg. 2014, 147, 1604-1611. [CrossRef] [PubMed]

44. Shintani, Y.; Ohta, M.; Iwasaki, T.; Ikeda, N.; Tomita, E.; Kawahara, K.; Ohno, Y. Predictive factors for postoperative acute exacerbation of interstitial pneumonia combined with lung cancer. Gen. Thorac. Cardiovasc. Surg. 2010, 58, 182-185. [CrossRef] [PubMed]

45. Suzuki, H.; Sekine, Y.; Yoshida, S.; Suzuki, M.; Shibuya, K.; Yonemori, Y.; Hiroshima, K.; Nakatani, Y.; Mizuno, S.; Takiguchi, Y.; et al. Risk of acute exacerbation of interstitial pneumonia after pulmonary resection for lung cancer in patients with idiopathic pulmonary fibrosis based on preoperative high-resolution computed tomography. Surg. Today 2011, 41, 914-921. [CrossRef] [PubMed]

46. Yano, M.; Sasaki, H.; Moriyama, S.; Hikosaka, Y.; Yokota, K.; Kobayashi, S.; Hara, M.; Fujii, Y. Post-operative acute exacerbation of pulmonary fibrosis in lung cancer patients undergoing lung resection. Interact. Cardiovasc. Thorac. Surg. 2012, 14, 146-150. [CrossRef] [PubMed]

47. Committee for Scientific Affairs, T.J.A.f.T.S.; Masuda, M.; Kuwano, H.; Okumura, M.; Amano, J.; Arai, H.; Endo, S.; Doki, Y.; Kobayashi, J.; Motomura, N.; et al. Thoracic and cardiovascular surgery in Japan during 2012: Annual report by The Japanese Association for Thoracic Surgery. Gen. Thorac. Cardiovasc. Surg. 2014, 62, 734-764. [CrossRef]

48. Sato, T.; Kondo, H.; Watanabe, A.; Nakajima, J.; Niwa, H.; Horio, H.; Okami, J.; Okumura, N.; Sugio, K.; Teramukai, S.; et al. A simple risk scoring system for predicting acute exacerbation of interstitial pneumonia after pulmonary resection in lung cancer patients. Gen. Thorac. Cardiovasc. Surg. 2015, 63, 164-172. [CrossRef] [PubMed]

49. Sato, T.; Watanabe, A.; Kondo, H.; Kanzaki, M.; Okubo, K.; Yokoi, K.; Matsumoto, K.; Marutsuka, T.; Shinohara, H.; Teramukai, S.; et al. Long-term results and predictors of survival after surgical resection of patients with lung cancer and interstitial lung diseases. J. Thorac. Cardiovasc. Surg. 2015, 149, 64-69. [CrossRef] [PubMed]

50. Chang, J.Y.; Senan, S.; Paul, M.A.; Mehran, R.J.; Louie, A.V.; Balter, P.; Groen, H.J.; McRae, S.E.; Widder, J.; Feng, L.; et al. Stereotactic ablative radiotherapy versus lobectomy for operable stage I non-small-cell lung cancer: A pooled analysis of two randomised trials. Lancet Oncol. 2015, 16, 630-637. [CrossRef]

51. Yamaguchi, S.; Ohguri, T.; Ide, S.; Aoki, T.; Imada, H.; Yahara, K.; Narisada, H.; Korogi, Y. Stereotactic body radiotherapy for lung tumors in patients with subclinical interstitial lung disease: The potential risk of extensive radiation pneumonitis. Lung Cancer 2013, 82, 260-265. [CrossRef] [PubMed]

52. Ueki, N.; Matsuo, Y.; Togashi, Y.; Kubo, T.; Shibuya, K.; Iizuka, Y.; Mizowaki, T.; Togashi, K.; Mishima, M.; Hiraoka, M. Impact of pretreatment interstitial lung disease on radiation pneumonitis and survival after stereotactic body radiation therapy for lung cancer. J. Thorac. Oncol. 2015, 10, 116-125. [CrossRef] [PubMed]

53. Yoshitake, T.; Shioyama, Y.; Asai, K.; Nakamura, K.; Sasaki, T.; Ohga, S.; Kamitani, T.; Yamaguchi, T.; Ohshima, K.; Matsumoto, K.; et al. Impact of Interstitial Changes on Radiation Pneumonitis After Stereotactic Body Radiation Therapy for Lung Cancer. Anticancer Res. 2015, 35, 4909-4913. [PubMed]

54. Ghatol, A.; Ruhl, A.P.; Danoff, S.K. Exacerbations in idiopathic pulmonary fibrosis triggered by pulmonary and nonpulmonary surgery: A case series and comprehensive review of the literature. Lung 2012, 190, 373-380. [CrossRef] [PubMed] 
55. Sakamoto, S.; Homma, S.; Kawabata, M.; Kono, T.; Seki, K.; Nakata, K.; Yoshimura, K. Fatal acute exacerbation of idiopathic pulmonary fibrosis/usual interstitial pneumonia initially in the right lung after surgery lobectomy for left lung cancer. Nihon Kokyuki Gakkai Zasshi 2004, 42, 760-766. [PubMed]

56. King, T.E., Jr.; Bradford, W.Z.; Castro-Bernardini, S.; Fagan, E.A.; Glaspole, I.; Glassberg, M.K.; Gorina, E.; Hopkins, P.M.; Kardatzke, D.; Lancaster, L.; et al. A phase 3 trial of pirfenidone in patients with idiopathic pulmonary fibrosis. N. Engl. J. Med. 2014, 370, 2083-2092. [CrossRef] [PubMed]

57. Iwata, T.; Yoshida, S.; Nagato, K.; Nakajima, T.; Suzuki, H.; Tagawa, T.; Mizobuchi, T.; Ota, S.; Nakatani, Y.; Yoshino, I. Experience with perioperative pirfenidone for lung cancer surgery in patients with idiopathic pulmonary fibrosis. Surg. Today 2015, 45, 1263-1270. [CrossRef] [PubMed]

58. Iwata, T.; Yoshida, S.; Fujiwara, T.; Wada, H.; Nakajima, T.; Suzuki, H.; Yoshino, I. Effect of Perioperative Pirfenidone Treatment in Lung Cancer Patients With Idiopathic Pulmonary Fibrosis. Ann. Thorac. Surg. 2016, 102, 1905-1910. [CrossRef] [PubMed]

59. Iwata, T.; Yoshino, I.; Yoshida, S.; Ikeda, N.; Tsuboi, M.; Asato, Y.; Katakami, N.; Sakamoto, K.; Yamashita, Y.; Okami, J.; et al. A phase II trial evaluating the efficacy and safety of perioperative pirfenidone for prevention of acute exacerbation of idiopathic pulmonary fibrosis in lung cancer patients undergoing pulmonary resection: West Japan Oncology Group 6711 L (PEOPLE Study). Respir. Res. 2016, 17, 90. [CrossRef] [PubMed]

60. Kawasaki, H.; Nagai, K.; Yoshida, J.; Nishimura, M.; Nishiwaki, Y. Postoperative morbidity, mortality, and survival in lung cancer associated with idiopathic pulmonary fibrosis. J. Surg. Oncol. 2002, 81, 33-37. [CrossRef] [PubMed]

61. Sekine, Y.; Sakairi, Y.; Yoshino, M.; Koh, E.; Hata, A.; Suzuki, H.; Yoshino, I. The impact of combined pulmonary fibrosis and chronic obstructive pulmonary disease on long-term survival after lung cancer surgery. Thorac. Cardiovasc. Surg. 2014, 62, 332-337. [CrossRef] [PubMed]

62. Park, J.; Kim, D.S.; Shim, T.S.; Lim, C.M.; Koh, Y.; Lee, S.D.; Kim, W.S.; Kim, W.D.; Lee, J.S.; Song, K.S. Lung cancer in patients with idiopathic pulmonary fibrosis. Eur. Respir. J. 2001, 17, 1216-1219. [CrossRef] [PubMed]

63. Bouros, D.; Hatzakis, K.; Labrakis, H.; Zeibecoglou, K. Association of malignancy with diseases causing interstitial pulmonary changes. Chest 2002, 121, 1278-1289. [CrossRef] [PubMed]

(C) 2018 by the author. Licensee MDPI, Basel, Switzerland. This article is an open access article distributed under the terms and conditions of the Creative Commons Attribution (CC BY) license (http:/ / creativecommons.org/licenses/by/4.0/). 